\title{
Understanding Source Use by Undergraduate Post-Novice EFL Writers for the Sustainability Development of Academic Literacy: Abilities, Challenges, and Strategies
}

\author{
Weihong Chen ${ }^{1,2}$ and Junju Wang ${ }^{1, *}$ \\ 1 School of Foreign Languages and Literature, Shandong University, Jinan 250100, China; \\ bellaweihongchen@outlook.com \\ 2 School of Foreign Languages, Quanzhou Normal University, Quanzhou 362000, China \\ * Correspondence: wangjunju@sdu.edu.cn
}

check for

updates

Citation: Chen, W.; Wang, J.

Understanding Source Use by Undergraduate Post-Novice EFL Writers for the Sustainability Development of Academic Literacy: Abilities, Challenges, and Strategies. Sustainability 2022, 14, 2108. https:// doi.org/10.3390/su14042108

Academic Editors: Lawrence Jun Zhang and Vincent T. Greenier

Received: 28 December 2021 Accepted: 10 February 2022 Published: 12 February 2022

Publisher's Note: MDPI stays neutral with regard to jurisdictional claims in published maps and institutional affiliations.

Copyright: () 2022 by the authors Licensee MDPI, Basel, Switzerland. This article is an open access article distributed under the terms and conditions of the Creative Commons Attribution (CC BY) license (https:// creativecommons.org/licenses/by/ $4.0 /)$.

\begin{abstract}
Source use by L2 writers is a significant topic of research in L2 writing. However, scant attention has been given to source use by undergraduate post-novice L2 writers. In contrast to undergraduate novice L2 writers who have just arrived at university and who often have little knowledge of source use and academic writing, undergraduate post-novice L2 writers are those who have achieved some proficiency in source use in academic writing assignments and have got some experience of writing from sources as they progress in their university studies (Keck, 2014; Wette, 2017). In this study, we examined source use by Chinese Year 3 undergraduate EFL writers through an analysis of their source use in essays and their perceptions of the challenges and strategies. The instances of source use in essays written by the students $(N=59)$ were analyzed in terms of source-use types, accuracy, and functions, which were then compared with those by novice and highly experienced writers in other studies. A subset of the students $(\mathrm{N}=25)$ were interviewed to understand their perceptions of the challenges and the strategies in their source-based writing processes. The analysis of the students' essays revealed that $71.4 \%$ of the instances of source use were paraphrases, and the majority of the instances of source use were of satisfactory quality, while a small portion were of poor quality, including exact copying (i.e., plagiarism), patchwriting, omitting references, or misrepresenting source information. The students used sources primarily to introduce or illustrate a point. An analysis of the interviews showed that the students had difficulty in searching for, understanding, and integrating sources and that they employed various strategies to cope with these challenges. This study enriches our understanding of undergraduate post-novice L2 writers' abilities and the successive challenges when writing from sources, which has implications for the development of academic writing instruction and which will help students address these challenges and facilitate the sustainable development of their abilities to write from sources.
\end{abstract}

Keywords: source use; challenges; strategies; undergraduate post-novice EFL writers

\section{Introduction}

Source use by second language (L2) writers has been a topic of long-standing interest in the field of second language writing. In recent decades, as a result of substantial relevant research, inappropriate source use by novice L2 writers has increasingly been reconceptualized as a reflection of a developmental stage of academic literacy [1,2] and a revelation of the difficulties that they encounter [3], rather than textual plagiarism [4] or transgressive intertextuality [5]. Due to this reconceptualization, attention has been increasingly paid to the novice L2 writers' choices of source-use types [6-9] and their views on challenges [3,10,11] and strategies [12-17] when writing from sources, with the primary goal of providing instruction to help the students hone this core, complicated, and advanced academic literacy [18,19]. 
Most previous research has focused on the appropriateness of source use by undergraduate novice L2 writers in integrated L2 writing tests and disciplinary L2 writing assignments at English-medium universities. However, the issue of whether undergraduate novice L2 writers make progress in writing from sources during their subsequent university studies remains largely underexplored. Undergraduate novice L2 writers are those undergraduate inexperienced L2 writers who have just arrived at university and who often have little knowledge of source use in academic writing and little experience of writing from sources $[1,3,18,19]$. In contrast to undergraduate novice L2 writers, undergraduate post-novice L2 writers are those who have achieved some proficiency in source use in academic writing assignments and have accumulated some experience of writing from sources as they advance beyond the first two or three years of their undergraduate studies $[3,18]$. Although it is difficult to give precise definitions of "undergraduate novice L2 writers" and "undergraduate post-novice L2 writers", as students who have progressed in their university studies may greatly vary in their level of ability and perceptions of source-based writing, it is necessary to examine and understand the current abilities of this group of L2 writers and their needs for instruction. Furthermore, there has also been a paucity of naturalistic research on source use by a large cohort of undergraduate L2 writers outside of English-dominated educational contexts and societies [19]. To contribute to the literature on this group of students and to gain insights into providing better, beneficial instruction, guidelines, and practice, this study examined source use by a group of fifty-nine Chinese Year 3 undergraduate EFL writers who have obtained some experience of writing from sources in English. It combined a detailed textual analysis of the students' essays with text-based interviews with the students.

\section{Review of the Literature}

\subsection{L2 Writers' Abilities to Write from Sources: Source-Use Types, Functions, and Accuracy}

A substantial body of relevant research has focused on different types and patterns of source use adopted by novices in integrated L2 writing tasks (i.e., L2 reading-to-write tasks or integrated L2 reading/writing assessments). Some comparative studies have revealed the significant roles played by text difficulty [20], writing proficiency [21], linguistic background $[8,22,23]$, and task type [8] in the students' choices of source-use types, including direct quotations, exact copy (i.e., plagiarism), paraphrases, and summaries. For example, Keck's [23] analysis of four types of paraphrasing in summaries written by L1 and L2 writers demonstrated that L2 writers more frequently copied extensively from sources and that L1 writers more often revised the source language moderately or substantially. However, in contrast to the findings reported in the above-listed studies, some research on source use in integrated L2 writing tests has found that the participants' choices of source-use types were generally similar across English proficiency levels and linguistic backgrounds [24-26]. For example, Hyland's [24] analysis of 125 first-year undergraduates' essays found few differences between the L1 and L2 writers' source use and that vague references, patchwriting, and confusion between paraphrases and quotations were common among both L1 and L2 writers. Weigle and Parker [26] examined source use in essays written by L2 writers with low, intermediate-low, intermediate-high, and high English language proficiency and discovered that both the topics and the language proficiency had a limited effect on the participants' source use and their patterns of textual borrowing. Though these conclusions are inclusive, these studies shed profound light on undergraduate L2 writers' employment of source-use types in writing.

Previous research has not only paid attention to students' choices of source-use types in integrated L2 writing tests but has also given prominence to their decisions about sourceuse types and the purposes for source use in disciplinary L2 writing assignments and dissertations. Some of the studies have reported that the participants often relied on direct quotations [2,27,28], patchwriting [1,29], and sentence-level paraphrasing [29] and that they used sources to serve a limited range of functions in writing $[6,10,30,31]$, all of which indicated the novice L2 writers' limited abilities to write from sources. 
Over recent years, the issue of source-use accuracy in source-based writing has aroused researchers' interest. According to previous research $[3,10,19,32]$, an instance of source use is coded as accurate if it correctly represents the information or ideas in the original text, including both the reporting of facts and the conveying of concepts, ideas, and arguments. Researchers have increasingly explored aspects of source use (e.g., source-use types, functions, and quality) by novice L2 writers [6,10,17,32]. For example, Neumann et al. [10] examined the source-use types, accuracy, and functions in 128 essays written by 73 firstyear L2 writers. They [10] found that the participants employed the method of indirect source-use (i.e., paraphrases and summaries) with or without citations most frequently and that their source use was of moderate quality. The study also reported that the participants mainly used source information to introduce and elaborate on an idea. Additionally, Uludag et al. [32] investigated the source use in 111 essays written by undergraduate L2 writers, including the amount of source use, the language used to represent the source information, and the accuracy of the representation of the source information. They [32] found that the majority of students substantially reformulated source information and accurately expressed the meaning of source information in essays.

To date, the majority of prior studies have provided a detailed description of inexperienced L2 writers' abilities to write from sources under controlled conditions or in natural settings, while their subsequent development of these abilities remains largely underexplored [3]. Specifically, little is known about the current abilities of undergraduate post-novice L2 writers who have shown some proficiency in source use in writing but have not yet acquired the abilities to write from sources.

\subsection{L2 Writers' Strategies Used in the Source-Based Writing Processes}

A line of studies has described a range of complex cognitive skills that L2 writers employ when reading and integrating sources in writing [18]. For example, through an analysis of an undergraduate L2 writer's logs and stimulated recalls, Ruiz-Funes [33] discovered that the participant iteratively deployed the following strategies: synthesizing, monitoring, structuring, elaborating, planning, writing, revising, and editing. Through think-aloud protocols and retrospective interviews, Yang and Shi [16] explored how six master's students engaged in the process of writing a summary. They found [16] that the participants recursively engaged in six writing sub-processes to differing degrees, including the sub-processes of verbalizing what is being written, planning to write a summary, referring to sources, reading what has been written, reviewing their written summaries, and commenting on sources. Plakans and Gebril [34] used a mixed-methods approach to explore undergraduate L2 students' processes of integrated L2 writing tests. They [34] revealed that students used the strategies of translating, summarizing, and rereading to improve their understanding and used sources to help develop their ideas, to shape their opinions, to support their language choices, and to organize the structure of their writing.

Some studies have focused on students' reading processes and have found that reading strategies exerted an important effect on students' processes of and performance in writing from sources [13,15,35]. For example, McCulloch [13] examined two L2 postgraduate students' reading processes and found that the participants differed in the ways that they elaborated on sources and drew inferences about sources as well as in the ways that they made intertextual connections across sources. He [13] concluded that the students decisions about source use occurred early in their reading processes, which might lead to their different levels of source engagement later in their writing processes. Plakans [15] used think-aloud protocols and interviews to explore the reading strategies used by twelve non-native English students who composed an integrated L2 writing task. She [15] divided the students' reading strategies into five categories: goal-setting for reading given sources, cognitive processing, global strategies, metacognitive strategies, and mining strategies. Cognitive-processing strategies, also referred to as local or bottom-up reading strategies, are word-level comprehension strategies, such as rereading words or slowing the reading pace. 
Global strategies are global comprehensive strategies, such as skimming to understand the gist or recognizing the text structure. Metacognitive strategies concern the students' highlevel processing of given sources and their self-regulating of their reading processes, such as by recognizing lack of comprehension or confirming understanding. Mining strategies involve the students' rereading of given sources to select information to use in writing, such as by rescanning sources for ideas to use in writing. In the study, she [15] found that cognitive-processing strategies were most often used, followed by global and mining strategies. She [15] also uncovered that high-scoring students used more mining and global strategies, suggesting that reading is integral to the process and performance of integrated L2 writing tasks. Yamada [35] analyzed 54 summaries written by 27 Japanese English-major students and found that a higher degree of inferential thinking when reading helped the writers better reorganize source information.

Moreover, research has also found that the processes of source reading and integration were interactive and interdependent [36], which entailed a hybrid cognitive operation of comprehending and constructing $[37,38]$ and involved higher-order shared or overlapping skills and processes of reading and writing [39]. For example, the studies by Plakans [14] and Yang [40] both investigated the process of integrated L2 writing tasks and discovered that the participants deployed the strategies of organizing, selecting, and connecting in both their reading and their writing processes, providing support for the construct of discourse synthesis [41].

\subsection{L2 Writers' Perceptions of Challenges in the Source-Based Writing Processes}

Previous studies have identified the challenges that undergraduate novice L2 writers face when reading and integrating sources to write. When reading sources, L2 writers, particularly those with low L2 reading abilities and/or low L2 language proficiencies, have difficulty understanding source texts [36,42,43], identifying the main points, information, and ideas within sources [21,44], and selecting appropriate information from sources into their writing [10]. Reading sources to write a research paper in L2 seems challenging for many L2 writers as they may be overwhelmed by the amount and word length of the reading materials $[45,46]$. Furthermore, when integrating sources into L2 writing, novices have trouble paraphrasing and summarizing source information [10]. This may be due to internal factors, such as the students' failure to fully understand the value of paraphrasing [27], limitations in linguistic resources and in paraphrasing skills [3,47], and incomplete understanding of source texts [1,29]. It may also be caused by external factors, such as time constraints [2,17] and workload pressure [17]. Finally, L2 writers may feel uncertain about the difference between their own ideas and the source content [17]. Consequently, these challenges often lead to their overreliance on direct quotations, exact copying, and/or patchwriting when writing from sources.

\subsection{Effect of Instruction and Experience on L2 Writers' Performance in Writing from Sources}

In their synthesis of research of writing from sources, Cummings et al. [18] claimed that students' abilities to write from sources varied according to such factors as content knowledge, domain knowledge, writing and, educational experiences. In particular, the students' proficiency in source use in academic writing usually develops gradually as they progress in their undergraduate studies [3,48-50], through instruction, learning, and experience [51-53]. Empirical studies have observed the importance of academic writing instruction and experience to L2 writers' performance in writing from sources [25,51-53]. For example, through detailed textual analysis of essays written before and after instruction, Wette [52] uncovered a significant increase in the incidence of accurate summaries and a decrease in the proportion of copying (i.e., plagiarism), although students' efforts to use sources were sometimes not successful. Keck [25] analyzed 227 summaries written by undergraduate L1 writers of English and L2 writers and found that in both the L1 and L2 groups, novice writers more often copied verbatim from sources than their peers with more years of experience in writing. Through textual analysis and interviews, Sun [53] 
examined source use in research papers written by first-year and second-year master's students and found group differences in their choices of source-use types. The results of her study [53] revealed that owing to instruction and their experience in academic writing, the group of second-year master's students had higher levels of citing awareness and domain knowledge, which led to the higher incidence of direct quotations and paraphrases in their papers. The influence of experience can also be discovered in the rhetorical purposes for which L2 writers' use sources. For example, through textual analysis of published research papers and interviews with scholars, Hyland [54] and Mansourizadeh, and Ahmad [55] both found that published scholars used summaries with citations for a variety of rhetorical purposes. In contrast, research has reported that inexperienced L2 writers seldom interacted with sources [3] and employed sources primarily to display knowledge by attributing knowledge, information, a finding, or an idea to a particular source $[6,9,30,31]$.

\section{Methodologies of Previous Studies of Source Use by L2 Writers}

The research on the L2 students' use of sources can be divided into two types. The first one is to do with controlled studies using integrated L2 writing tasks (i.e., L2 readingto-write tasks or integrated L2 reading/writing assessments). In the controlled studies, L2 writers are asked to read and use sources given by researchers to write an argumentative essay or summary under test or test-like conditions, e.g., $[6-10,14,16]$. The second one is to do with naturalistic studies, which are studies of take-home writing [22] or studies in academic writing in naturalistic settings, in which L2 writers read and use self-selected sources for an academic writing assignment, e.g., [17,31,33,45,46].

Most of the studies to date have focused on either the source-based written products or the processes by L 2 writers engaged in integrated L2 writing tasks or disciplinary L2 writing assignments. They have mostly relied on textual analysis to investigate L2 writers' use of sources in written products, e.g., [1,2,6,8,9], and think-aloud protocols, interviews, or logs to examine L2 writers' processes of source-based writing, e.g., [1,3,10,14-16,45]. Moreover, they have often combined text-based interviews to elicit the participants' perspectives and experiences when writing from sources in L2, e.g., $[1,3,10]$. In terms of textual analysis, the aspects of students' use of sources (e.g., source-use types, functions, accuracy, and sources) are analyzed, e.g., [3,6-10,32]. Source-use types are identified and coded according to the students' linguistic modifications of the source information to differing degrees and whether they provide a reference to an instance of source use, based on which source-use functions are further analyzed. Source-use accuracy is coded and analyzed in terms of whether the meaning of the source information or the ideas are accurately represented, e.g., $[3,10,19,32]$.

Given the methods used in the majority of prior relevant studies, this study adopted textual analysis and text-based interviews to investigate both the source-based written products and the writing processes.

\section{Rationale and Aims}

As shown in the previous discussion of the relevant research, few studies of L2 writers' source use have been concerned with undergraduate post-novice L2 writers. Undergraduate post-novice L2 writers can be described as those who have advanced beyond the first two or three years of their undergraduate studies and who have demonstrated some proficiency in source use in academic writing and have accumulated some experience of writing source-based disciplinary assignments $[3,48]$. The majority of these students might have received academic writing instruction, including a unit on source use, during their undergraduate studies $[3,48]$. As previous empirical studies have found that academic writing instruction and experience exerted an influence on L2 writers' performance in writing using sources, e.g., [48,49,51-53], this group of L2 writers may make strides to some extent in their abilities to write from sources and may vary in their understanding of source use and development of paraphrasing skills $[3,25,48]$. Therefore, their current abilities 
to write from sources and instructional needs need to be better understood to provide additional academic writing instruction as well as enhance the quality of the instruction.

The main purpose of this present study was to examine source use by Chinese Year 3 undergraduate EFL writers in an English writing assignment. It investigated their abilities to write from sources through examining aspects of source use (e.g., source-use types, accuracy, and functions) in their English essays and comparing their source use with that of highly experienced and novice writers in other studies, as well as eliciting their perceptions of challenges and strategies in their source-based writing processes. It was guided by the following three research questions:

(1) What is the level of ability of the undergraduate EFL writers in source-based writing in terms of source-use types, functions, and accuracy?

(2) What challenges do the undergraduate EFL writers face in their source-based writing processes?

(3) What strategies do the undergraduate EFL writers employ in their source-based writing processes?

\section{Methods}

This was a naturalistic study of source use by Chinese Year 3 undergraduate EFL writers at a comprehensive university in China. We aimed to investigate the students' use of self-selected sources in an English writing assignment and their views on the challenges and strategies. To enhance our findings, we adopted a mixed-methods approach [56]. Qualitative methods were used to analyze the interviews with the students, while counting the number of source-use types, the accuracy scores of the source use, and the frequencies of source-use functions in the students' essays accounted for the quantitative part of the study.

\subsection{Research Context and Participants}

This study was conducted at Quanzhou Normal University, a public institution located in southeast China with an enrolment of approximately 200 undergraduates majoring in English annually. At this university, English majors need to complete language- and culture-related courses, such as English Listening, Oral English, English Grammar, English Writing, English Intensive Reading, English Extensive Reading, Translation, An Introduction to Linguistics, British Literature, and American Literature. Of these courses, English Writing, An Introduction to Linguistics, British Literature, American Literature and Culture of English-Speaking Countries often use a combination of instructional lectures, reading materials, and source-based writing assignments. Particularly, the writing courses, including Basic English Writing and Advanced English Writing, totaled $144 \mathrm{~h}$ of instruction and were compulsory from the third semester to the sixth semester over Year 2 and Year 3. In these two writing courses, students are often asked to write essays on a given topic every month, most of which are source-based essays of about 600 to 1200 words.

This study took place in the fifth semester, 2021. The participants of this study were all Year 3 English majors who began to take the course of Advanced English Writing throughout the fifth semester, 2021. The students in this study were contacted through their instructors.

Of the approximately 130 Year 3 English majors that we approached, a total of fiftynine students (fifty-three female and six male), aged between 20 and 22, volunteered to take part in the study. All the participants gave their written consent to allow their writing be used anonymously as data in this study and agree to be interviewed after the completion of their writing. They all spoke Mandarin as their first language, commenced learning English at primary school and had over 13 years' experience of English learning. None of them had ever traveled abroad.

Based on the participants' grades on two of China's national standardized English tests, the TEM-4 (Test for English Majors Band 4) and the CET-6 (College English Test Band 6), their language proficiency can be described as being in the lower-intermediate (twelve students), intermediate (twenty-three students), upper-intermediate (eighteen students), 
and advanced levels (six students). All the participants had successfully completed the course of Basic English Writing over Year 2, which included instruction on source use. Their grades on the source-based writing assignment for this course varied from B+ (75-79\%) to $A+(95-100 \%)$, and their grades on this course of Basic English Writing varied from B+ (75-79\%) to A (85-94\%). They had also successfully completed 11 disciplinary courses that included source-based writing assignments. In accordance with the definition of undergraduate post-novice L2 writers made, as all the participants of this study had received academic writing instruction, acquired some proficiency in source use in writing assignments, and had some experience in source-based writing, these participants can be described as undergraduate post-novice EFL writers.

\subsection{Data Collection}

During the end of September 2021, the instructor of Advanced English Writing asked the students in the study to complete a source-based writing assignment on a given topic, China's Fight against COVID-19 Winning International Fame, and submit it via e-mail within two weeks. The assignment required the students to write an expository essay of about 700-900 words in English, in which the students were asked to use self-selected sources to summarize the effective measures taken by China to contain the pandemic and the international praise for China's efforts as well as express their opinions on the topic. It also asked the students to acknowledge their use of sources by providing a reference to the author and a reference list of the sources used. The first researcher obtained the writing prompt and the requirements from the instructor, which are shown in Appendix A.

Moreover, the instructor informed the students that the quality of their source-based essays would be scored to evaluate three aspects of source-based writing: (a) holistic ratings of content development in terms of ideas and logic, language use, and structural organization (as in English proficiency tests); (b) source-use accuracy in terms of whether the source information was accurately represented; and (c) the extent of verbatim copying from the sources (i.e., the extent of plagiarism and patchwriting in their essays).

Three weeks after the students in the study had been given the assignment, they sent their scored essays and the sources used to the first researcher via e-mail. The number of essays was fifty-nine and the essay length ranged from 703 to 1075 words, with an average of 783 words $(S D=87.7)$. The essays were marked by their instructors. Their grades on the assignment ranged from $\mathrm{B}+(75-79 \%)$ to $\mathrm{A}(85-94 \%)$, and the average grade was A- (80-84\%).

During the study period, text-based interviews were conducted to explore and understand the students' perspectives of their source-based writing processes and source use in written products. From the cohort of the participants who had indicated their willingness to be interviewed on their written consent, 25 students were randomly selected to participate in the interviews. Each volunteer student was interviewed once. The time of the interviews was set after the students' submission of their scored essays and sources. Each interview was conducted by the first researcher at a location chosen by the students. Each interview lasted between 30 and $60 \mathrm{~min}$. The scored essays and sources that had been previously sent to the first researcher were used during the interviews to aid the students' reflection of their source-based writing processes and source use in essays. The interviews were guided by open-ended questions, which allowed the students to share their thoughts about the writing task requirements, the challenges they had faced in their writing processes, and the strategies they had used to search for and locate sources, understand and process sources, paraphrase, and integrate relevant information in their essays, as well as their choices of source-use types and the reasons and purposes for the source use. Guided questions are shown in Appendix B. All the interviews were audio-recorded and subsequently transcribed. 


\subsection{Data Analysis}

\subsubsection{Textual Analysis of Source Use in Essays}

We manually identified the instances of source use in all the participants' essays. As all the participants provided a reference list in their essays and provided the sources they had used, it was possible to locate and underline the instances of source use through the participants' reference to the authors' names and years of publication and through comparisons between the instances of source use in the participants' essays and the sources they had used.

The total number of the instances of source use in essays by all the participants was 440 . We developed and refined each coding scheme to analyze the following aspects of students' source use in essays: (1) source-use types, (2) accuracy of the source information used, and (3) functions of the source information used.

Source-use Types: We adapted the coding scheme of source-use types from Gebril and Plakans [21] and Neumann et al. [10] and identified source-use types in terms of the extent of verbatim copying from sources (e.g., plagiarism, patchwriting) as well the extent of the reformulation of the source information using the students' own words. We developed the coding scheme of source-use types in the students' essays in two steps. Initially, it comprised four broad categories: direct quotations (defined as strings of words copied with quotation marks), exact copying (i.e., plagiarism, which was defined as extensive copying from sources and without quotation marks), patchwriting (defined as revisions of sentences from sources by revising clause structures, using synonyms, or blending the students' own words with short strings of words copied), and paraphrases (defined as reformulations of source information using the students' own words). Due to the blurry boundaries between paraphrase and summary [27], the summaries in the students' essays were coded as paraphrases. Then, based on whether an instance of source use was cited, we further divided these source-use categories into eight subcategories: direct quotations with or without reference; exact copying with or without reference; patchwriting with or without reference; and paraphrases with or without reference. We also coded the instance of source use with implicit citation where the students referred to an original source text in one sentence and continued to use chunks of information from the same source text in the following sentence. The complete coding scheme is shown in Table 1.

Source-use Accuracy: While conducting the analysis of source use in the students' essays, we found that the students sometimes misunderstood, omitted, exaggerated, or distorted the meaning of source information. For example, if the source text indicated that some neighboring countries praised China for its efforts to fight against the pandemic of COVID-19, the writers might conclude that China received high praise from the majority of foreign countries globally, even though the source text did not mention it. For that reason, we adopted the two-point scale developed by Neumann et al. [10] to assess source-use accuracy in the students' essays, as follows:

2: Accurate representation of the source text (e.g., correctly reporting facts or representing the meaning of the source information or ideas);

1: Somewhat accurate representation of the source text (e.g., accurately conveying the meaning of the source information, with some errors in grammar but comprehensible to a reader; accurately conveying part of the meaning of the source information, with some of the meaning of the source information omitted; somewhat exaggerating the intended meaning of the source information);

0: Misrepresentation of the source text (e.g., fabricating facts; distorting the meaning of the source information).

Source-use Functions: We first differentiated whether the source information used was relevant to the essay. If it was relevant, we then analyzed the function it served in the essays. Based on the coding scheme of Neumann et al. [10] and Wette [3,17], we developed and refined the coding scheme of the source-use functions to the present study, as follows:

Introduction of a point: The students drew on a source to introduce a point. 
Table 1. Coding categories for analysis of source-use types.

\begin{tabular}{|c|c|c|c|}
\hline Code & Description & $\begin{array}{l}\text { Source Text, with Information/Language Used } \\
\text { in an Example Underlined }\end{array}$ & $\begin{array}{l}\text { Example, with the Instances of } \\
\text { Source Use Underlined }\end{array}$ \\
\hline Direct quotation with reference & $\begin{array}{l}\text { Strings of words copied with } \\
\text { quotation marks and with reference } \\
\text { to the author or the source of } \\
\text { information }\end{array}$ & $\begin{array}{l}\text { “This is a very good public health } \\
\frac{\text { practice", said Dr. Michael Ryan. }}{\text { (Hua Xia, 19 February 2020) }}\end{array}$ & $\begin{array}{c}\text { In a report issued by Hua Xia with } \\
\text { Xinhua News Agency on } \\
19 \text { February 2020, } \\
\text { Dr. Michael Ryan stated that } \\
\text { "This is a verygood public } \\
\text { health practice". (Student 23) }\end{array}$ \\
\hline $\begin{array}{l}\text { Direct quotation } \\
\text { without reference }\end{array}$ & $\begin{array}{l}\text { Strings of words copied with } \\
\text { quotation marks but without } \\
\text { reference to the author or the source } \\
\text { of information }\end{array}$ & $\begin{array}{l}\text { “Those measures on movement restriction } \\
\frac{\text { have delayed the dissemination of the }}{\text { outbreak by two or three days }} \\
\text { within China, and two or three weeks } \\
\text { outside China", said Sylvie Briand, head of the } \\
\text { WHO's Global Infectious Hazard Preparedness } \\
\text { division.(Chinese Global Television Network, } \\
\text { 19 February 2020) }\end{array}$ & $\begin{array}{l}\text { "Those measures on movement } \\
\text { restriction havedelayed the } \\
\frac{\text { disseminationof the outbreak by }}{\text { two or three dayswithin China, }} \\
\frac{\text { and two or three weeks }}{\text { outside China". (Student 11) }}\end{array}$ \\
\hline Exact copying with reference & $\begin{array}{l}\text { Extensive copying without } \\
\text { quotation mark; with reference to } \\
\text { the author or the source } \\
\text { of information }\end{array}$ & $\begin{array}{l}\frac{\text { The measures taken by China have }}{\text { effectively prevented the spread of }} \\
\text { the epidemic caused by the novel } \\
\text { coronavirus (COVID-19). (Chinese Global } \\
\text { Television Network, 19 February 2020) }\end{array}$ & $\begin{array}{l}\text { According to an article published by } \\
\text { CGTN on } 19 \text { February } 2020 \text {, } \\
\text { the measures taken by China have } \\
\text { effectively prevented the spread of } \\
\text { the epidemic caused by the novel } \\
\text { coronavirus (COVID-19). (Student } 58 \text { ) }\end{array}$ \\
\hline $\begin{array}{l}\text { Exact copying } \\
\text { without reference }\end{array}$ & $\begin{array}{l}\text { Extensive copying without } \\
\text { quotation mark; without reference } \\
\text { to the author or the source } \\
\text { of information }\end{array}$ & $\begin{array}{l}\frac{\frac{\text { It has become a public consensus that }}{\text { isolation is the most effective measure }}}{\text { to prevent the spread of the virus }} \\
\text { before a vaccine is developed". (Hu, 2020, p. 37) }\end{array}$ & $\begin{array}{l}\text { It has become a public consensus } \\
\frac{\text { that isolation is the most effective }}{\text { measure to prevent the spread }} \\
\frac{\text { of the virus before a vaccine }}{\text { is developed. (Student } 11 \text { ) }}\end{array}$ \\
\hline Patchwriting with reference & $\begin{array}{l}\text { Revisions of sentences from sources } \\
\text { by revising clause structures, using } \\
\text { synonyms, or blending the students' } \\
\text { own words with short strings of } \\
\text { words copied; with reference to the } \\
\text { author or the source of information }\end{array}$ & $\begin{array}{l}\text { The World Health Organization (WHO) said } \\
\text { Tuesday that } \\
\text { measures to restrict people's movement } \\
\frac{\text { in China amid the COVID-19 outbreak }}{\text { are a correct strategic and tactical approach. }} \\
\text { (Hua Xia, 19 February 2020) }\end{array}$ & $\begin{array}{l}\text { In a report issued by Hua Xia with } \\
\text { Xinhua News Agency on } \\
19 \text { February 2020, the World Health } \\
\text { Organization said that } \\
\frac{\text { China's actions during COVID-19 }}{\text { are a right strategy and tactic. }} \\
\text { (Student 38) }\end{array}$ \\
\hline Patchwriting without reference & $\begin{array}{l}\text { Revisions of sentences from sources } \\
\text { by revising clause structures, using } \\
\text { synonyms, or blending the students' } \\
\text { own words with short strings of } \\
\text { words copied; without reference to } \\
\text { the author or the source } \\
\text { of information }\end{array}$ & $\begin{array}{l}\text { The government emphasized that } \\
\text { people's lives and health must come first. } \\
2020, \mathrm{p} .8)\end{array}$ & $\begin{array}{l}\text { Furthermore, } \\
\text { the government stressed that it } \\
\text { would put the lives of the people } \\
\text { in the first place. (Student 21) }\end{array}$ \\
\hline Paraphrase with reference & $\begin{array}{l}\text { Reformulations of source } \\
\text { information using the students's } \\
\text { own words; with reference to the } \\
\text { author or the source of information }\end{array}$ & $\begin{array}{c}\text { "Boldest action should include community } \\
\text { action: Thinking that this does not concern me } \\
\text { is not an option", Kluge added.(Meredith, S., } \\
17 \text { March 2020) }\end{array}$ & $\begin{array}{l}\text { Meredith S. reported on } 17 \text { March } 2020 \\
\text { that Kluge advised that every } \\
\text { community join in the fight against } \\
\text { the epidemic, for the prevention and } \\
\text { control of the epidemic was every } \\
\text { person's responsibility. (Student 17) }\end{array}$ \\
\hline $\begin{array}{l}\text { Paraphrase with } \\
\text { implicit reference }\end{array}$ & $\begin{array}{l}\text { Reference to an original source in } \\
\text { one paraphrased sentence and } \\
\text { continued paraphrases of sentence } \\
\text { from the same source in the } \\
\text { following sentence }\end{array}$ & $\begin{array}{l}\text { UN Secretary-General Guterres said that "From } \\
\text { the start, the World Health Organization } \\
\text { provided factual information and scientific } \\
\text { guidance that should have been the basis for a } \\
\text { coordinated global response. Unfortunately, } \\
\text { many of these recommendations were not } \\
\text { followed. Additionally, in some circumstances, } \\
\text { there was a rejection of facts and an ignoring of } \\
\text { the guidance". (Zamir, A.A., 2020, p.1) }\end{array}$ & $\begin{array}{l}\text { Guterres, who was UN } \\
\text { Secretary-General, expressed his } \\
\text { concerns for the situation and said } \\
\text { that WHO had strived to release } \\
\text { relevant information and provide } \\
\text { support. Many countries failed to } \\
\text { accept what had happened and } \\
\text { refused to take the advice provided by } \\
\text { WHO. (Student 41) }\end{array}$ \\
\hline Paraphrase without reference & $\begin{array}{l}\text { Reformulations of source } \\
\text { information using the students' } \\
\text { own words; without reference to the } \\
\text { author or the source of information }\end{array}$ & $\begin{array}{l}\text { The United Nations health agency has advised } \\
\text { all countries to adopt a mix of interventions } \\
\text { based on an analysis of the local situation and } \\
\text { context, with containment as a major pillar. } \\
\text { (Meredith, S., } 17 \text { March 2020) }\end{array}$ & $\begin{array}{l}\text { All countries around the world should } \\
\text { attach great importance to } \\
\text { containment of the pandemic and } \\
\text { combine various measures on the } \\
\text { basis of their own conditions. } \\
\text { (Student 7) }\end{array}$ \\
\hline
\end{tabular}

Repetition of a point: The students repeated a point introduced in a previous instance of the source use.

Example: The students used source information to illustrate a point.

Elaboration: The students used source information to elaborate on a point mentioned previously.

\subsubsection{Analysis of Interview Data}

The interview transcripts were analyzed thematically by reading and rereading the participants' responses about their source use in the written products and writing processes. The initial round of coding was to capture the main themes. The identification of the main 
themes was primarily coded and grouped by the research and interview questions, with the themes or categories identified previously in the related literature used as a frame of reference. For the second research question, the framework in Neumann et al. [10] was adopted and refined, while for the third research question, the categories from Wette $[3,17]$ were used and developed. The second round of coding was to identify the sub-categories of each main theme. The two researchers coded the interview data independently and then discussed to solve disagreements about the thematic codes. The final version of the thematic codes included "challenges faced in the source-based processes", "search strategies ", "reading strategies", and "source-integration strategies", each of which was then divided into subcategories. To ensure intra-rater reliability, one L2 writing expert, whose positive feedback and advice contributed to the data analysis process, was invited to appraise the coding scheme. The final version of the coding scheme is shown in Table 2.

Table 2. Coding categories for analysis of interview data.

\begin{tabular}{|c|c|c|}
\hline Code & Definition & Example Extracts from the Interviews \\
\hline $\begin{array}{l}\text { 1. Challenges faced } \\
\text { 2. Search strategies }\end{array}$ & Difficulty encountered & I feel that paraphrasing is difficult. \\
\hline Defining search terms & Formulating keywords to search & $\begin{array}{l}\text { I extracted keywords from the } \\
\text { writing prompt. }\end{array}$ \\
\hline Evaluating search results & Scanning search results to locate sources & $\begin{array}{l}\text { I read titles and introductions of sources } \\
\text { at the search results page. }\end{array}$ \\
\hline Evaluating sources & $\begin{array}{l}\text { Selecting a source to use in writing or } \\
\text { abandoning it after skimming }\end{array}$ & $\begin{array}{c}\text { I found these sources useless and closed } \\
\text { them down. }\end{array}$ \\
\hline \multicolumn{3}{|l|}{ 3. Reading strategies } \\
\hline Understanding the gist & $\begin{array}{l}\text { Understanding and generalizing the gist } \\
\text { of a source }\end{array}$ & $\begin{array}{l}\text { I found the source was about China's } \\
\text { transport control. }\end{array}$ \\
\hline Identifying important information & $\begin{array}{c}\text { Focusing on key information within } \\
\text { a source }\end{array}$ & $\begin{array}{l}\text { I noticed the isolation measure in the } \\
\text { source. I felt it was very important. } \\
\text { I found these sources were all concerned } \\
\text { with positive comments. For example, I }\end{array}$ \\
\hline Making comparisons across sources & $\begin{array}{l}\text { Noticing the links between information } \\
\text { across sources }\end{array}$ & $\begin{array}{l}\text { noted that many countries expressed } \\
\text { their compliments. Then I thought of } \\
\text { Singapore's praise for China, so I } \\
\text { returned to the source to compare. }\end{array}$ \\
\hline Focusing on a phrase for use & $\begin{array}{l}\text { Noticing a phrase and thinking of using it } \\
\text { later in the writing }\end{array}$ & $\begin{array}{l}\text { I noticed the phrase "cut off" and thought } \\
\text { of reusing it later in my writing. }\end{array}$ \\
\hline Focusing on a sentence for use & $\begin{array}{l}\text { Noticing a sentence and thinking of using } \\
\text { it later in the writing }\end{array}$ & $\begin{array}{l}\text { The sentence denotes the decrease in } \\
\text { patients. I then decided to reuse it in } \\
\text { my writing. }\end{array}$ \\
\hline Using electronic tools & Using electronic tools to facilitate reading & $\begin{array}{c}\text { I used Google Translate to help quickly } \\
\text { understand the source. }\end{array}$ \\
\hline \multicolumn{3}{|l|}{ 4. Source-integration strategies } \\
\hline Making an outline & $\begin{array}{l}\text { Making an outline to facilitate } \\
\text { source integration }\end{array}$ & $\begin{array}{l}\text { I occasionally switched between } \\
\text { windows to draw up an outline. }\end{array}$ \\
\hline Vocabulary-level paraphrasing & $\begin{array}{c}\text { Borrowing words / phrases from a source } \\
\text { to use in writing }\end{array}$ & $\begin{array}{l}\text { I borrowed the phrase "under control" } \\
\text { from the source. }\end{array}$ \\
\hline Sentence-level paraphrasing & $\begin{array}{l}\text { Paying attention to summary sentences in } \\
\text { sources and paraphrasing them } \\
\text { in writing }\end{array}$ & $\begin{array}{l}\text { I intentionally searched for summary } \\
\text { sentences in a source to paraphrase. }\end{array}$ \\
\hline
\end{tabular}

\section{Results}

In this section, the results of the study are presented to answer our research questions. The first question was concerned with an examination of the abilities of the students to write from sources. It was answered through analysis of the source-use types, the accuracy, and the functions in the students' essays, together with comparisons between the source use by the students in this study and that by novice and highly experienced writers in prior 
work. The results of the analysis of the interview data were used to answer the second and third questions.

\subsection{Students' Use of Sources in Essays}

Four hundred and forty instances of source use in fifty-nine essays were identified and analyzed. The number of the instances of source use per essay ranged from 3 to 16, with an average of 9 per 1000 words. The source use in the students' essays can be divided into nine types, including direct quotations with or without reference, exact copying with or without reference, patchwriting with or without reference, paraphrases with or without reference, and paraphrases with implicit reference. An analysis of the data showed that the students used these nine types of source use to differing degrees, as shown in Table 3. This table illustrates that the students most frequently paraphrased the meaning of the source information $(\mathrm{n}=314,71.4 \%$ ), indicating that the source information had been transformed by using their own words. However, the students did not cite all the instances of paraphrases in their essays. As shown in Table 3, the paraphrases with reference and with implicit reference accounted for $55.7 \%(n=245)$ of all of their source-use instances, while the paraphrases without reference made up $15.7 \%(n=69)$. The two least commonly found source-use types were direct quotations with reference $(n=19,4.3 \%)$ and without reference $(n=5,1.1 \%)$. Patchwriting with reference and without reference accounted for just $7.9 \%(n=35)$ in the present study. A further $15.1 \%(n=67)$ of the instances of source use featured exact copying with and without reference.

Table 3. Source-use types in EFL writers' essays.

\begin{tabular}{lcc}
\hline \multicolumn{1}{c}{ Source-Use Types } & Frequency & \% \\
\hline Direct quotation & & \\
$\quad$ Direct quotation (R) & 19 & 4.3 \\
$\quad$ Direct quotation (NR) & 5 & 1.1 \\
Total & 24 & 5.4 \\
Exact copying & 50 & \\
$\quad$ Exact copying (R) & 17 & 31.4 \\
$\quad$ Exact copying (NR) & 67 & 15.1 \\
Total & & \\
Patchwriting & 20 & 4.5 \\
$\quad$ Patchwriting (R) & 15 & 3.4 \\
$\quad$ Patchwriting (NR) & 35 & 7.9 \\
Total & 213 & 48.4 \\
Paraphrase & 32 & 7.3 \\
Paraphrase (R) & 69 & 15.7 \\
Paraphrase (IR) & 314 & 71.4 \\
Paraphrase (NR) & & \\
Total & & \\
\hline Note: R reference; NR = no reference; IR = implicit reference. &
\end{tabular}

The incidence of paraphrases in this study was much higher than that found in prior work involving novice L2 writers, e.g., [1,3,8,10,23,25], while the incidence of quotations, patchwriting, and exact copying was much lower than the findings reported in those previous studies. However, in contrast to the source use by published scholars [54,55], the students of this study seldom paraphrased source information across multiple sources.

We also analyzed the functions of the source information used in the students' essays and display the results in Table 4 . This table shows that the students used the source information to fulfil four types of functions in their essays, with introducing a point and providing an example to illustrate a point being the two most frequent types of function found in the data. In this respect, the students' source use in this study was similar to that of inexperienced L2 writers in other studies, e.g., [1,6,8-10,17]. In contrast, the published articles by experienced writers used sources for a much broader range of rhetorical purposes [54,55]. 
Table 4. Source-use functions in EFL writers' essays.

\begin{tabular}{ccc}
\hline Function & Frequency & $\%$ \\
\hline Introduction & 196 & 44.5 \\
Repetition & 23 & 5.2 \\
Example & 154 & 35.0 \\
Elaboration & 52 & 11.8 \\
Irrelevant & 15 & 3.4 \\
\hline
\end{tabular}

An analysis of the source-use accuracy in terms of the representation of source information revealed that the mean accuracy scores of the direct quotations, exact copying, patchwriting, and paraphrases were $2(\mathrm{SD}=0), 1.8(\mathrm{SD}=0.5), 1.5(\mathrm{SD}=0.6)$, and $1.6(\mathrm{SD}=0.3)$, respectively, as shown in Table 5 . The results were a little more satisfactory than that reported by Neumann et al. [10], indicating that the students in the study accurately integrated sources into their essays to a greater extent. However, the results of this study also evidenced that certain instances of the students' source use included some minor mistakes. Such inaccuracies could have been due to their exaggeration of the intended meaning of a source, the misunderstanding of some information, the omission of key information, incorrect language choices, or incorrect syntactical structure.

Table 5. Mean accuracy scores of EFL writers' use of sources in essays.

\begin{tabular}{ccc}
\hline Source-Use Types & Mean & SD \\
\hline Direct quotation & 2 & 0 \\
Exact copying & 1.8 & 0.5 \\
Patchwriting & 1.5 & 0.6 \\
Paraphrase & 1.6 & 0.3 \\
\hline
\end{tabular}

6.2. Students' Views of Challenges in Their Source-Based Writing Processes

\subsubsection{Challenges Faced in the Search Processes}

The students spoke of uncertainties and the challenges that they believed lingered on in their source-based writing processes. When searching for sources, several students felt difficulty in defining search terms. The excerpts in Examples 1 and 2 illustrate this difficulty.

Example 1. Sometimes I can not get sources needed. Maybe, er, it is because that the search term that I enter is too general. For example, once I used a sentence as search terms and the searching ended in failure. (Student 7)

Example 2. Formulating keywords sounds difficult... find that I'm not good at selecting keywords when searching for information....I really don't know which keywords to use. (Student 55)

\subsubsection{Challenges Faced in the Reading Processes}

One such challenge that the students faced was the difficulty in understanding sophisticated sources. This may be due to their limited repertoire of technical words, topic familiarity, or patience, as the following quotations from the interviews illustrate:

Example 3. I find some articles include too many long sentences and new words .... [They are] too difficult to read. I often lost patience and stopped to look for Chinese sources instead. (Student 47)

Example 4. I have little knowledge about the topic... You know, it often takes me too much time to look up words in dictionaries.... The [reading] process always makes me feel so tired and defeated. (Student 10)

Example 5. Well, some articles are too long ... and some articles feature complex structure and rhetorical style... . Sometimes, I really don't know what meaning the author intends to express in that sentence. (Student 37) 
Even when students gained an understanding of sources, they found it challenging to identify and select which important information to use. They mentioned that, sometimes, they were overwhelmed by the wealth of information available online and felt anxious about how to select relevant information to serve their writing. Their concerns for the selection of source information are illustrated in the following two quotations from the interviews:

Example 6. There are a substantial number of relevant sources available. And, so much information included in a single source.... know I have to read through all information carefully before I select some (to use in my writing). I have to think it over. [The selection process is] very difficult. (Student 20)

Example 7. The most difficult thing is to select appropriate information. The sources are too long and include too much information. ... I have to select key information instead of covering all information in my writing. (Student 11)

\subsubsection{Challenges Faced in the Source-Integration Processes}

The students also described the challenges that they encountered when crafting a paraphrase to integrate source information into their essays. Using acceptable language to accurately convey the meaning of source information, showing their own understanding of source information, and organizing source information into a piece of coherent writing all posed difficulties for these students. They recalled the difficulty in searching for appropriate vocabulary and syntactical structure within their minds or in dictionaries as well as the brainstorming for a coherent organizational structure for their writing, as the following three quotations reveal:

Example 8. Paraphrasing is difficult. I spent a lot of time thinking over how to formulate a paraphrase. [There are] lots of things to consider, such as which word and phrase to select, how to enrich syntactical structure, how to paraphrase source information across sources. ... (Student 13)

Example 9. How to paraphrase source information accurately [is difficult]. I often feel uncertain whether I make an accurate summary of the gist or whether I succeed in synthesizing the information with my own understanding. I have no idea whether some of my paraphrases distort the author's intended meaning. (Student 41)

Example 10. How to paraphrase source meaning across sources is difficult, particularly when the sources differ in ideas and viewpoints. .. You have to combine source information and your own ideas coherently and logically. (Student 12)

The final challenge that the students confronted was their uncertainty about whether to provide a reference to some of the source information used. In particular, they believed that some instances of source use were more the result of their efforts to extend their own ideas than the borrowing of the original source information or words. Moreover, they also felt concerned about how to extend an instance of source use beyond a single sentence without needing to offer a new reference to the source text. Their uncertainties are shown in the following quotations from the interviews:

Example 11. I have to provide a reference to direct quotations. But, I sometimes feel confused about whether to cite a paraphrase, (since that) some instances of paraphrases were generated largely based on my own ideas. (Student 19)

Example 12. There are various views about what can be regarded as plagiarism.... I know I have to cite an instance of source use [to avoid plagiarism]. But, for the following instance of source use based on the same source text, maybe, there are also various views on the necessity [to offer a reference]. (Student 58)

In brief, for these students, various challenges lay before them in their processes of searching for, understanding, and integrating sources into their writing. When searching for sources, some of the students found it challenging to define appropriate search terms. 
When processing selected sources to use in writing, understanding complicated source texts, and identifying important source information caused concern among these students. Moreover, when integrating source information into essays, these students also found it difficult to use appropriate and accurate language to craft paraphrases and felt uncertain about citing some instances of source use.

\subsection{Students' Views of Strategies in Their Source-Based Writing Processes 6.3.1. Search Strategies}

The students reported using a range of specific strategies when writing from sources in English. With regard to the search processes, the students recalled their use of strategies for keyword formulation. They remembered that they often extracted keywords from the writing prompt. When encountered with unsuccessful attempts to search, they would then change the search query by extracting keywords from sources scanned in preceding searches and from prior knowledge. They would also use specific keywords instead of general ones. The excerpts in Examples 13 and 14 demonstrate these strategies.

Example 13. Keyword (selection) is very important. For example, when searching for sources about measures (adopted by China), I copied and pasted keywords from the writing prompt and got many sources needed. But this way (of keyword selection) did not work for my search for positive international comments. I then reformulated keywords based on a source that I had read.... I also added WHO to the search term, for I got to know its praise for China's efforts on the news. (Student 56)

Example 14. I first used the search term "COVID-19". Then I realized it's too general; so I added "measures" and "China" (to the search term). (Student 23)

When evaluating search results to locate sources, they mentioned that they often scanned the titles and introductions of sources and paid great attention to the sources displayed at the top of a search engine search results page, as noted in the following example from the interviews.

Example 15. (When scanning the search results), I scanned topics and clicked in those that I felt would be useful to my writing. Particularly, I tended to visit the links at the top of the list of the search results. (Student 6)

All of the students identified two main criteria used during reading, evaluating, and selecting a source to use in their essays: relevance and reliability. The criterion "relevance" was related to their perceptions of the potential utility of a source. Some students described relevant sources as those which provided factual information and details for content development in their writing. "Relevance" also referred to information, concepts, or ideas that could contribute to extending their own ideas and shaping their own opinions. This could be in the form of paraphrases or phrase borrowing that provided conceptual or linguistic scaffolding to the students' writing. For example, many students noticed the concept "a community with a shared future for mankind" in sources and decided to incorporate it into their discussions about personal opinions about the theme of the writing, as shown in Example 16.

Example 16. To me, source relevance is very important. The content of a source should be well corresponded to the topic of my writing. For example, I borrowed the concept " $a$ community with a shared future for mankind" from a source, for it was compatible with my opinion that I intended to express in the conclusionary part of my essay. (Student 21)

The other criterion used was reliability, which concerned their perceptions of the quality of the source content and the authoritativeness of the sources of information. The students preferred to use quality-assured sources from official and authoritative websites and databases. For example, a source was considered authoritative if it was a government report or from a government page.

In addition to these two main criteria for source evaluation and selection, some students also emphasized other source criteria such as whether a source was interesting to read, 
whether it was easy to understand, or whether it featured good language, organizational structure, and logic. These criteria are illustrated in the excerpts in Examples 17 and 18.

Example 17. Selecting a source that is interesting and easily comprehensible sounds important to me. I suppose, if you're not interested in the content of a source, or if you find a source difficult to understand, it is impossible to use it in your writing. (Student 55)

Example 18. I tend to select sources including advanced vocabulary and well-structured sentences. I believe language use is very important in English writing; so I often take language into consideration when selecting sources to read and use (in my writing). (Student 53)

\subsubsection{Reading Strategies}

Students then described how they read a selected source to cull relevant information and look for appropriate language. They first scanned and/or rescanned its titles, subtitles, the first paragraph, or the first few sentences of each paragraph for the major purpose of getting the gist of the source. Then, they continued to rescan the source globally; to identify important information; to highlight and/or take note of important words, phrases, or sentences; and to connect chunks of information with their own writing. These reading strategies seemed to be prevalent among the students, as noted in the following excerpt of the interviews.

Example 19. I first scanned titles of each section to understand the gist. Then, I rescanned the source to identify and select key, relevant information...I paid particular attention to both the introduction and conclusionary paragraphs of the source.... also took notes of important words, phrases and information and thought of how to use them later in my writing. (Student 7)

Moreover, some students reported that they compared similarities and differences in the content and viewpoints across sources or connected source information with their own prior knowledge. This is shown in the following examples.

Example 20. I find that many sources share similar descriptions or viewpoints. For example, some of the sources all describe China's open and transparent attitudes... When reading a source about China's measures to contain the pandemic, I thought of my own experiences. (Student 22)

Example 21. I tried to seek similarities in sources and expressed my understanding of the similarities in the notes.... When reading sources, I also planned how to integrate the information (that I culled from sources) with my prior knowledge of the pandemic. (Student 44)

The students also described their reliance upon electronic tools and resources to facilitate their understanding. For example, all the students pointed to their use of online translators, online dictionary portals, digital dictionaries, digital note-taking tools, or visualenhancement resources (e.g., highlighting, font sizes, and underlining). These electronic tools and resources helped them to understand the sources, particularly when the rhetorical style of a source impeded their comprehension. The excerpts in Examples 22 and 23 exemplify their dependence on electronic tools and resources.

Example 22. I used Baidu Translate to facilitate my understanding....Besides, I often looked up words in digital dictionaries. (Student 57)

Example 23. I often use a Mind Map application to help understand and memorize important information across sources. (Student 12)

\subsubsection{Source-Integration Strategies}

The students recalled that the next stage of their writing processes was source integration, which involved extracting source information or ideas from sources or notes, making decisions about source-use types, constructing accurate and acceptable paraphrases, and 
incorporating these paraphrases into their essays. The strategies that they reported using were similar in many ways. For example, all the students attached great importance to useful expressions in sources, with the aim of seeking language support to extend their own ideas or interpret the information noticed. Particularly, some students indicated that extracting words and phrases from the titles of the sources was a quick and efficient approach. Inspired by these expressions, they then formulated patchwriting and/or paraphrases. Their focus on expressions in sources was illustrated in Example 24.

Example 24. I tend to rescan titles of the sources to select important words (to use in my writing).... I borrowed key words from the source to convey my own ideas.I extracted many useful expressions (from the source), such as "high importance", "swift response", "openness", "transparency", and "timely and accurate information release". I took down these expressions and then used them to formulate paraphrases.

(Student 15)

Some students reported making an outline based on their notes and the sources that they had read. When making their outline, they planned the main points of each paragraph, the organizational structure, and the source information needed to support their points. Guided by their outlines, they then reread self-selected sources and notes to reformulate information by using their own words in essays. This was noted in Examples 25 and 26.

Example 25. (When reading sources), I tried to summarize the gist, main points and similar viewpoints shared in sources.By rereading these summaries, I then made an outline for content development (in my writing)...The outline helped me incorporate the source information with my own ideas.

(Student 20)

Example 26. After reading all sources selected, I reviewed the notes that I had taken; then I made an outline on how to express my own viewpoints (in the writing).

(Student 21)

Some students mentioned that they occasionally scanned sources for summary sentences and managed to paraphrase these sentences into their essays. They believed that this strategy greatly reduced the difficulty in crafting a paraphrase, as shown in the following example.

Example 27. I often pay special attention to the abstract of an article, for the abstract includes ready-made summaries... (When writing), I attempt to paraphrase summary sentences from the source. (Student 59)

\section{Discussion}

This research is unique for its focus on the undergraduate post-novice L2 writers' use of sources; these are students who have received academic writing instruction and have some experience of writing from sources in English. With the aim of understanding the current abilities of this group of students and their instructional needs, this research examined the instances of source use in essays written by fifty-nine Year 3 undergraduate EFL writers, as well as their perceptions of the challenges and strategies in their sourcebased writing processes.

The first research question concerned the abilities of the students to write from sources. An analysis of the students' essays revealed the source-use types, the accuracy, and the functions. As shown in the data, the most common source-use type adopted by the students was paraphrase, which was followed sequentially by exact copying, patchwriting, and direct quotation. The results indicated the students' awareness of paraphrasing source content to avoid plagiarism and their careful attention to the assignment requirements. For example, Student 45 explained in the interview that "Paraphrasing source information is an appropriate way of source use, which I believe is up to the teacher's expectation". The students' major use of paraphrases in this study was consistent with the findings reported in Wette [3], which revealed that over $70 \%$ of the citations in post-EAP disciplinary L2 writing 
were paraphrases of acceptable quality. On a more encouraging note, the incidence of patchwriting in the study was much lower than that in other studies studying inexperienced L2 writers $[1,3,8,10,23,25]$. A further analysis of the data revealed that a proportion of the instances of source use did not offer a reference. The results are surprising as citing the sources used was a requirement of the assignment. Moreover, using sources to introduce a point and to illustrate a point were the two most frequent functions in the students' essays. This was in accordance with the findings in previous studies, e.g., $[3,6,10,17,30]$. However, few of the students interacted with the sources, which was quite different from the highly experienced writers (e.g., published scholars and graduate students), who actively engaged with sources with confidence $[54,55]$. This may be partly the consequence of the genre of this assignment, which required students to sift through and exemplify source information to explain a topic.

The results also showed that the mean accuracy score of each source-use type was above $1.5 / 2$, indicating that in most cases, the students were able to represent the source information accurately. The source-use accuracy in the study was a little higher than that reported in Neumann et al. [10]. However, it was consistent with the findings of Cummings et al. [19] and Wette [3,17], all of which revealed that students mostly correctly paraphrased source content. Previous research focused predominantly on examining the extent of patchwriting and exact copying in L2 writers' writing instead of how accurately L2 writers present source content and ideas. The findings of this study therefore offer a useful insight and make a significant contribution to the literature on source use by L2 writers.

Taken as a whole, the participants' use of sources in essays was characterized by a high incidence of paraphrases, a low occurrence of patchwriting, exact copying, and direct quotations, and satisfactory quality. Their level of ability appears more advanced than that of first-year, inexperienced L2 writers in other studies, e.g., [1,6,10,23,25], but was lower compared with that of highly experienced writers in previous studies, e.g., [54,55]. The results of this study therefore indicated that the students in this study had gained abilities to write from sources to some extent and that they were still at the stage of the development of academic literacy rather than having yet to acquire these abilities.

Our second research question was related to the students' perceptions of current challenges in their source-based writing processes. The findings of this study showed that students experienced trouble in their processes of searching for, reading, and integrating sources. First, when searching for sources, defining search terms posed a difficulty to some students. Secondly, difficulties arose when students understood difficult sources and when they culled relevant information from a vast body of sources located. Thirdly, the students found that using appropriate and accurate language to paraphrase source information and to organize source information and their own ideas with coherence and logic was difficult. Moreover, the students sometimes felt uncertain about the necessity to offer a reference. They occasionally had trouble clearly differentiating the boundaries between their own ideas and thoughts and the source content. These uncertainties and difficulties were corroborated in our analysis of the source use in the above, which revealed that a small number of the instances of source use were exact copying, patchwriting, and direct quotations and that students sometimes failed to represent source information correctly. Students' difficulties and challenges in the processes of source reading and integration were confirmed in previous work $[3,10,17]$, while their difficulties in the search processes were seldom described in prior studies.

Our third research question asked about the students' use of strategies in their sourcebased writing processes. From the interviews, the students described their strategies for searching for, reading, and integrating sources. First, our findings showed the strategies that the students used to formulate keywords and to judge search results. At the same time, the students used a range of source selection and evaluation criteria, with relevance and reliability being the dominant ones. These two source evaluation criteria were consistent with the findings in previous studies $[3,17,49,57]$. With regard to the reading processes, the students' reading strategies mainly included skimming for the gist of a source, scanning to 
select important information, and focusing on certain words, phrases, and sentences. These reading strategies showed their tendency to use both global and bottom-up reading strategies, which were in consonance with the findings in Plakans [15]. In particular, the students significant attention to important words, phrases, and sentences while reading showed their writerly reading of language forms [58] and the tendency to seek linguistic scaffolding from source texts [34], indicating that they had moved beyond mere comprehension toward brainstorming on how to use the expressions and source information in their essays. It also suggested that the reading and source-integration processes were in fact interactive and interdependent $[14,36,38,40,41]$. Furthermore, some students both established intertextual links between information across sources and made elaborations on source information and ideas using prior knowledge. These are two higher-order and deeper-level cognitive reading strategies that have been associated with more successful L2 writers [13]; they are of great importance in gaining a complete understanding of sources and in constructing coherent mental representations of information across multiple sources [59].

Regarding the source-integration processes, the results showed that students often relied on short strings of words or sentences in sources and the outline that they had structured. Their use of these two strategies was indicative of the effects of the English writing instruction that they had received during Year 2. In particular, the vocabulary- and sentence-level paraphrasing strategies may have been stimulated in part by the languagerelated courses that they had completed over Year 1 and Year 2. The reason for this is that, in Chinese EFL learning contexts, instructors often emphasize the importance of memorization, imitation, and the reuse of formulaic phrases and well-structured sentences from readings, which is valued as a useful and effective learning strategy for acquiring language and literacy. This conclusion was confirmed in previous relevant studies in Chinese EFL learning contexts [19,60,61].

Finally, the analysis of the students' reading strategies demonstrated the students dependence on electronic tools to improve comprehension as well as to facilitate source integration. For example, online translators and dictionaries enabled the students to better understand the sources and to seek out appropriate lexical choices to craft paraphrases quickly and efficiently, while digital note-taking tools helped them comprehend, memorize, and reorganize important language resources and source information. Taken together, the use of technology profoundly affected the manner in which the students read, understood, and integrated sources into their writing. The results therefore shed profound light on the significance of technology. While such activities may be viewed as compensatory strategies [57], they nevertheless proved effective, as the average grade of the students essays was A- (80-84\%). The findings on students' use of technology were confirmed in Nguyen and Buckingham [57], Wette [3], and Wette [17]. However, they were seldom documented in McCulloch [13] and Plakans [15], both of whom analyzed the students' engagement with print source texts.

\section{Conclusions}

This study presents a detailed account of the current abilities of undergraduate postnovice EFL writers to write from sources, the challenges faced, and the strategies adopted. The analysis of the students' essays and interviews revealed that the majority of the instances of source use were appropriate and accurate and that the participants succeeded in using a variety of strategies to cope with various challenges encountered in their sourcebased writing processes. The findings also showed their inexperience in some aspects of source use, such as their occasional use of exact copying and patchwriting, their failure to cite some instances of source use, and their misrepresentation of source information.

The significance of this study is twofold. On the one hand, unlike a number of previous studies focusing on either the source-based writing processes, e.g., [12-16] or the products, e.g., $[2,4,6-9,22]$ of novice writers with English as a second language, this study explored both the source-based processes and the products of undergraduate postnovice EFL writers. It is clearly able to provide us with useful information not found in 
relevant studies, either in controlled conditions or natural settings. It has illustrated not only students' source-use types, functions, and accuracy but also their understanding of and concerns about their source use in writing and source-based writing processes, which enriches our understanding of source use by undergraduate L2 writers. On the other hand, the findings of this study evidenced and confirmed the effect of instruction and experience on student performance in writing from sources [48,49,51-53]. It also pointed to the need to offer additional academic writing instruction to Year 3 and Year 4 undergraduate L2 writers.

Based on the findings of the study, pedagogical materials can be developed to facilitate the subsequent and sustainable development of the undergraduate L2 writers' abilities to write from sources throughout their undergraduate years. Firstly, given a small number of instances of inappropriate source use by the students, direct instruction should guide students to undertake the practice with an integral set of effective and appropriate sourceuse skills $[17,51]$, including appropriate ways of paraphrasing, summarizing, and quoting source texts. Secondly, due to the challenges that the students had faced when searching for sources, instruction is needed to help students learn to define specific and accurate search terms, use authoritative and targeted search engines and databases, and evaluate search results. Thirdly, to improve source-use accuracy and cope with the difficulties faced in both the reading and the source-integration processes, teachers can add the component of material reading to academic writing instruction and lead discussions on how to grasp and summarize the gist of a source, what important information to identify, how to evaluate information within and across sources, and what linguistic tools to use to transform source information or ideas. Moreover, teachers could also engage students in the interactive processes of reading and writing by teaching them to use discourse synthesis strategies (i.e., selecting, organizing, and connecting) [14,40,41]. These pedagogical efforts may help students gain an in-depth and complete understanding of sources, develop their repertoire of linguistic resources, and successfully deal with their source-based writing processes. Fourthly, given the limited range of source-use functions in the students' essays, explicit instruction should be provided to inform students of the wide range of functions that a source can be used to serve $[17,19]$.

The study has two limitations. First, the results of this study are context-specific and may not be generalizable, although our conclusions may resonate with instructors and undergraduate post-novice EFL writers in comparable education contexts. However, a detailed investigation of a specific context is necessary to examine and improve the effectiveness of the instruction, with the aim of helping students learn and sharpen their skills. Another limitation is that this study investigated the undergraduate post-novice EFL writers' abilities to write from sources at a certain point in time instead of examining how this group of students developed their skills over a long period. To provide support for the findings and conclusions reported in this study and to generate a better understanding of source use by undergraduate post-novice L2 writers, future studies can build upon this study by examining the correlations between the undergraduate post-novice L2 writers' performance in writing from sources and their language proficiency and L2 writing proficiency, as well as by exploring the development of their abilities to write from sources over longer periods.

The path toward mastering academic literacy is long for L2 writers, and much work still needs to be carried out to learn how L2 writers develop their abilities to write from sources during their undergraduate years and what guidance and support academic writing courses can offer to help students acquire the abilities. We hope that this study furthers the understanding of the undergraduate post-novice EFL writers' abilities to write from sources and the potential benefits of instruction.

Author Contributions: Conceptualization, W.C.; data collection, W.C.; formal analysis, W.C. and J.W.; writing - original draft, W.C.; writing-review and editing, W.C. and J.W. All authors have read and agreed to the published version of the manuscript. 
Funding: This work was supported by the National Social Science Fund of China by National Office for Philosophy and Social Sciences under Grant number 17AYY022.

Institutional Review Board Statement: This study was conducted according to the guidelines of the Declaration of Helsinki and approved by the Human Participants Ethics Committee of Shandong University, China.

Informed Consent Statement: Informed consent was obtained from all the subjects involved in the study.

Data Availability Statement: Data are available from the first author upon request. The data are not publicly available due to ethical considerations.

Conflicts of Interest: The authors declare no conflict of interest.

\section{Appendix A}

Essay prompts and requirements

Prompts: China has been complimented by many countries and international organizations on its effective control of COVID-19. Use self-selected sources to write an essay of about 700-900 words on the topic China's Fight against COVID-19 Winning International Fame. In the essay, you are expected to include (1) the effective measures used by China to contain the spread of COVID-19; (2) the positive international comments on what China has accomplished; and (3) your opinion on the topic.

Requirements: (1) cite the author or the source of information; (2) do not copy extensively from sources; and (3) provide a reference list of the sources used.

\section{Appendix B}

Interview questions

Introductory questions:

1. How many English writing courses have you taken in university?

2. What English writing courses have you taken this semester?

3. What disciplinary courses have you taken in university?

4. How many writing assignments requiring source use have you completed? Please give some examples.

The search process

5. Can you tell me how you went about searching for, locating, and selecting sources for the writing task?

6. How did you decide if a source text was useful?

The reading process

7. Can you tell me how you read the sources selected to use in writing?

8. What do you find easy during the reading process? Why?

9. What do you find difficult during the reading process? Why?

The source-integration process

10. Can you tell me how you integrate source information into writing?

11. Can you comment on each instance of your source use (as underlined by the interviewer)?

12. What do you find easy during the source-integration process? Why?

13. What do you find difficult during the source-integration process? Why?

\section{References}

1. Li, Y.Y.; Casanave, C.P. Two first-year students' strategies for writing from sources: Patchwriting or plagiarism? J. Second Lang. Writ. 2012, 21, 165-180. [CrossRef]

2. Petrić, B. Legitimate textual borrowing: Direct quotation in L2 student writing. J. Second Lang. Writ. 2012, 21, 102-117. [CrossRef]

3. Wette, R. Source text use by undergraduate post-novice L2 writers in disciplinary assignments progress and ongoing challenges. J. Second Lang. Writ. 2018, 37, 46-78. [CrossRef] 
4. Pecorari, D. Good and original: Plagiarism and patchwriting in academic second-language writing. J. Second Lang. Writ. 2003, 12, 317-345. [CrossRef]

5. Borg, E. Local plagiarisms. Assess. Eval. High. Educ. 2009, 34, 415-426. [CrossRef]

6. Lee, J.J.; Hitchcock, C.; Elliott Casal, J. Citation practices of L2 university students in first-year writing: Form, function, and stance. J. Engl. Acad. Purp. 2018, 33, 1-11. [CrossRef]

7. Lombardi, A. More is more: Explicit intertextuality in university writing placement exam essays. J. Engl. Acad. Purp. 2021, 50, 100955. [CrossRef]

8. Shi, L. Textual borrowing in second-language writing. Writ. Commun. 2004, 21, 171-200. [CrossRef]

9. Shi, L. Textual appropriation and citing behaviors of university undergraduates. Appl. Linguist. 2010, 31, 1-24. [CrossRef]

10. Neumann, H.; Leu, S.; McDonough, K. L2 writers' use of outside sources and the related challenges. J. Engl. Acad. Purp. 2019, 38, 106-120. [CrossRef]

11. Neumann, H.; Leu, S.; Mcdonough, K.; Crawford, B. Improving students' source integration skills: Does a focus on reading comprehension and vocabulary development work? J. Engl. Acad. Purp. 2020, 48, 100909. [CrossRef]

12. Karimi, M.N.; Alibakhshi, G. EFL learners' text processing strategies across comprehension vs. integration reading task conditions. System 2014, 46, 96-104. [CrossRef]

13. McCulloch, S. Investigating the reading-to-write processes and source use of L2 postgraduate students in real-life academic tasks: An exploratory study. J. Engl. Acad. Purp. 2013, 12, 136-147. [CrossRef]

14. Plakans, L. Discourse synthesis in integrated second language writing assessment. Lang. Test. 2009, 26, 561-587. [CrossRef]

15. Plakans, L. The role of reading strategies in integrated L2 writing tasks. J. Engl. Acad. Purp. 2009, 8, 252-266. [CrossRef]

16. Yang, L.X.; Shi, L. Exploring six MBA students' summary writing by introspection. J. Engl. Acad. Purp. 2003, 2, 165-192. [CrossRef]

17. Wette, W. Source-based writing in a health sciences essay: Year 1 students' perceptions, abilities and strategies. J. Engl. Acad. Purp. 2018, 36, 61-75. [CrossRef]

18. Cumming, A.; Lai, C.; Cho, H. Students' writing from sources for academic purposes: A synthesis of recent research. J. Engl. Acad. Purp. 2016, 23, 47-58. [CrossRef]

19. Cumming, A.; Yang, L.; Qiu, C.; Zhang, L.; Ji, X.; Wang, J.; Lai, C. Students' practices and abilities for writing from sources in English at universities in China. J. Second Lang. Writ. 2018, 39, 1-15. [CrossRef]

20. Kim, S.A. Characteristics of EFL readers' summary writing: A study with Korean university students. Foreign Lang. Ann. 2001, 34, 569-581. [CrossRef]

21. Gebril, A.; Plakans, L. Toward a transparent construct of reading-to-write tasks: The interface between discourse features and proficiency. Lang. Assess. Q. 2013, 10, 9-27. [CrossRef]

22. Doolan, S.M. An exploratory analysis of source integration in post-secondary L1 and L2 source-based writing. Engl. Specif. Purp. 2021, 62, 128-141. [CrossRef]

23. Keck, C. The use of paraphrase in summary writing: A comparison of L1 and L2 writers. J. Second Lang. Writ. 2006, 15, 261-278. [CrossRef]

24. Hyland, T.A. Drawing a line in the sand: Identifying the borderzone between self and other in EL1 and EL2 citation practices. Assess. Writ. 2009, 14, 62-74. [CrossRef]

25. Keck, C. Copying, paraphrasing, and academic writing development: A re-examination of L1 and L2 summarization practices. J. Second Lang. Writ. 2014, 25, 4-22. [CrossRef]

26. Weigle, S.; Parker, K. Source text borrowing in an integrated reading/writing assessment. J. Second Lang. Writ. 2012, 21, 118-133. [CrossRef]

27. Hirvela, A.; Du, Q. “Why am I paraphrasing? ": Undergraduate ESL writers' engagement with source-based academic writing and reading. J. Engl. Acad. Purp. 2013, 12, 87-98. [CrossRef]

28. Docherty, P. An exploratory study in the use of direct quotation by L2 entry level Bachelor students. J. Engl. Acad. Purp. 2019, 40, 26-40. [CrossRef]

29. Howard, R.M.; Serviss, T.; Rodrigue, T.K. Writing from sources, writing from sentences. Writ. Pedagog. 2010, 2, 177-192. [CrossRef]

30. Gao, J.; Picoral, A.; Staples, S.; Macdonald, L. Citation practices of L2 writers in first-year writing courses: Form, rhetorical function, and connection with pedagogical materials. Appl. Corpus Linguist. 2021, 1, 100005. [CrossRef]

31. Petric, B. Rhetorical functions of citations in high-and-low-rated master's theses. J. Engl. Acad. Purp. 2007, 6, 238-253. [CrossRef]

32. Uludag, P.; Lindberg, R.; McDonough, K.; Payant, C. Exploring L2 writers' source-text use in an integrated writing assessment. J. Second Lang. Writ. 2019, 46, 100670. [CrossRef]

33. Ruiz-Furies, M. The process of reading-to-write used by a skilled Spanish-as-a-foreign-language student: A case study. Foreign Lang. Ann. 1999, 32, 45-48. [CrossRef]

34. Plakans, L.; Gebril, A. A close investigation into source use in integrated second language writing tasks. Assess. Writ. 2012, 17, 18-34. [CrossRef]

35. Yamada, K. Comparison of two summary/text-integration writing tasks requiring different inferential processes. RELC J. 2002, 33, 142-156. [CrossRef]

36. Esmaeili, H. Integrated reading and writing tasks and ESL students' reading and writing performance in an English language test. Can. Mod. Lang. Rev. 2002, 58, 599-620. [CrossRef] 
37. Segev-Miller, R. Cognitive processes in discourse synthesis: The case of intertextual processing strategies. In Writing and Cognition: Research and Applications; Torrance, M., Van Waes, L., Galbraith, D., Eds.; Elsevier: Amsterdam, The Netherlands, 2007; pp. 231-250.

38. Plakans, L. Comparing composing processes in writing-only and reading-to-write test tasks. Assess. Writ. 2008, 13, 111-129. [CrossRef]

39. Plakans, L.; Liao, J.T.; Wang, F. "I should summarize this whole paragraph": Shared processes of reading and writing in iterative integrated assessment tasks. Assess. Writ. 2019, 40, 14-26. [CrossRef]

40. Yang, H. Toward a model of strategies and summary writing performance. Lang. Assess. Q. 2014, 11, 403-431. [CrossRef]

41. Nelson, N. Discourse synthesis: The process and the product. In Discourse Synthesis: Studies in Historical and Contemporary Social Epistemology; McInnis, R.G., Ed.; Praeger: Westport, CT, USA, 2001; pp. 379-396.

42. Asención Delaney, Y. Investigating the reading-to-write construct. J. Engl. Acad. Purp. 2008, 7, 140-150. [CrossRef]

43. Sawaki, Y.; Quinlan, T.; Lee, Y.W. Understanding learner strengths and weaknesses: Assessing performance on an integrated writing task. Lang. Assess. Q. 2013, 10, 73-95. [CrossRef]

44. Sutherland-Smith, W. Pandora's box: Academic perceptions of student plagiarism in writing. J. Engl. Acad. Purp. 2005, 4, 83-95. [CrossRef]

45. Stapleton, P. Writing in an electronic age: A case study of L2 composing processes. J. Engl. Acad. Purp. 2010, 9, 295-307. [CrossRef]

46. Xie, Q.; Lei, Y.Q. Diagnostic assessment of L2 academic writing product, process and self-regulatory strategy use with a comparative dimension. Lang. Assess. Q. 2021, 1-33. [CrossRef]

47. Shi, L. Rewriting and paraphrasing source texts in second language writing. J. Second Lang. Writ. 2012, 21, 134-148. [CrossRef]

48. Wette, R. L2 undergraduate students learning to write using sources: A trajectory of skill development. In Teaching Writing for Academic Purposes to Multilingual Students: Instructional Approaches; Storch, J., Wette, B.N., Wette, R., Eds.; Routledge: London, UK, 2017; pp. 99-112.

49. Thompson, C.; Morton, J.; Storch, N. Where from, who, why and how? A study of the use of sources by first year L2 university students. J. Engl. Acad. Purp. 2013, 12, 99-109. [CrossRef]

50. Bereiter, C.; Scardamalia, M. The Psychology of Written Composition; Erlbaum: Hillsdale, NJ, USA, 1987.

51. Du, Y. Effect of an EAP unit on EFL student effective and appropriate source-use skills. J. Engl. Acad. Purp. 2019, 40, 53-73. [CrossRef]

52. Wette, R. Evaluating student learning in a university-level EAP unit on writing using sources. J. Second Lang. Writ. 2010, 19, 158-177. [CrossRef]

53. Sun, Y. A study on citing practice in English academic writings by EFL learners. Foreign Lang. Res. 2016, 1, 132-136.

54. Hyland, K. Academic attribution: Citation and the construction of disciplinary knowledge. Appl. Linguist. 1999, 20, 341-367. [CrossRef]

55. Mansourizadeh, K.; Ahmad, U.K. Citation practices among non-native expert and novice scientific writers. J. Engl. Acad. Purp. 2011, 10, 152-161. [CrossRef]

56. Miles, M.B.; Huberman, A.M.; Saldaña, J. Qualitative Data Analysis: A Methods Sourcebook, 3rd ed.; Sage: Thousand Oaks, CA, USA, 2014.

57. Nguyen, Q.; Buckingham, L. Source-use expectations in assignments: The perceptions and practices of Vietnamese Master's students. Engl. Specif. Purp. 2019, 53, 90-103. [CrossRef]

58. Hirvela, A. Connecting Rading and Writing in Second Language Writing Instruction; University of Michigan Press: Ann Arbor, MI, USA, 2004.

59. Anmarkrud, Ø.; Bråten, I.; Strømsø, H.I. Multiple-documents literacy: Strategic processing, source awareness, and argumentation when reading multiple conflicting documents. Learn. Individ. Differ. 2013, 30, 64-76. [CrossRef]

60. Hu, G.W.; Lei, J. Investigating Chinese university students' knowledge of and attitudes toward plagiarism from an integrated perspective. Lang. Learn. 2012, 62, 813-850. [CrossRef]

61. Li, J.; Schmitt, N. The acquisition of lexical phrases in academic writing: A longitudinal case study. J. Second Lang. Writ. 2009, 18, 85-102. [CrossRef] 